\title{
HUBUNGAN TINGKAT KEPUASAN PASIEN ANTENATAL CARE (ANC) DENGAN MUTU PELAYANAN KESEHATAN DI WILAYAH KERJA KECAMATAN SOMBA OPU KABUPATEN GOWA
}

\author{
Fhirastika Annisha Helvian \\ Fakultas Kedokteran dan Ilmu Kesehatan UIN Alauddin Makassar \\ fhirastika.annisha@uin-alauddin.ac.id
}

\begin{abstract}
Abstrak
Salah satu tanggung jawab sektor kesehatan adalah menjamin tersedianya pelayanan kesehatan yang bermutu. Pengukuran tingkat kepuasan pasien antenatal care dilakukan dalam usaha perbaikan mutu pelayanan kesehatan di wilayah kabupaten Gowa. Penelitian ini bertujuan untuk mengetahui hubungan dan tingkat kepuasan pasien ANC terhadap mutu pelayanan kesehatan di Wilayah kerja Kecamatan Somba Opu Kabupaten Gowa tahun 2016. Jenis penelitiaan ini adalah kualitatif dengan pendekatan cross sectional. Metode penarikan sampel adalah simple random sampling dengan instrument penelitian berupa kuisioner. Sampel adalah ibu hamil yang melakukan pemeriksaan ANC di wilayah kerja kecamatan sombaopu Kabupaten Gowa. Hasil penelitian menunjukkan kepuasan pasien sudah baik dan adanya hubungan antara dimensi-dimensi mutu pelayanan dengan kepuasan pasien di wilayah kerja kecamatan sombaopu Kabupaten Gowa. Dengan itu diharapkan mutu pelayanan kesehatan di wilayah kerja kecamatan Sombaopu kabupaten Gowa terus dipertahankan dan ditingkatkan.

Kata Kunci : mutu pelayanan, tingkat kepuasan, Antenatal Care / ANC
\end{abstract}

\section{PENDAHULUAN}

Dewasa ini masalah kesehatan telah menjadi kebutuhan pokok bagi masyarakat. Dengan meningkat nya taraf hidup masyarakat, maka semakin meningkat pula tuntutan masyarakat akan kualitas kesehatan. Hal ini menuntut penyedia jasa pelayanan kesehatan seperti rumah sakit, puskesmas, dan klinik kesehatan untuk meningkatkan kualitas pelayanan yang lebih baik, tidak hanya pelayanan yang bersifat penyembuhan penyakit tetapi juga mencakup pelayanan yang bersifat pencegahan (preventif) untuk meningkatkan kualitas hidup serta memberikan kepuasan bagi konsumen selaku pengguna jasa kesehatan. ${ }^{1}$

Angka Kematian Ibu (AKI) merupakan indikator utama derajat kesehatan ibu dan ditetapkan sebagai salah satu tujuan Millenium Development Goals
(MDGs). Jumlah AKI di Indonesia masih tergolong sangat tinggi. Berdasarkan (SDKI 2012), rata-rata AKI tercatat mencapai 359 per 100.000 kelahiran hidup. Rata-rata kematian ini jauh melonjak dibanding hasil SDKI 2007, yang mencapai 228 per 100.000 kelahiran hidup. Peningkatan yang terjadi ini mengakibatkan sulitnya Indonesia dapat mencapai target MDGs yang ditetapkan yaitu 102 per 100000 kelahiran hidup pada tahun $2015 .^{2}$

Jika dibandingkan dengan AKI di negara-negara tetangga maka jumlah AKI di Indonesia sebanyak 228 per 100.000 kelahiran hidup masih tergolong tinggi. AKI di Singapura adalah 6 per 100.000 kelahiran hidup, AKI di Malaysia mencapai 160 per 100.000 kelahiran hidup, AKI di Vietnam sama seperti negara Malaysia, sudah mencapai 160 per 100.000 kelahiran 
hidup, Filipina 112 per 100.000 kelahiran hidup, dan Brunei 33 per 100.000 per kelahiran hidup. ${ }^{3}$

Hal ini dapat dihindari salah satunya dengan pemeriksaan kesehatan selama kehamilan yang dikenal dengan ANC (AnteNatal Care). Antenatal Care adalah pengawasan sebelum persalinan terutama ditujukan pada petumbuhan dan perkembangan janin dalam rahim. Upaya menurunkan AKI (hamil, melahirkan, dan nifas) sangat dibutuhkan pelayanan Ante Natal Care (ANC) yang berkualitas sesuai standar kebijakan Pemerintah, yaitu sekurang-kurangnya 4 kali selama masa kehamilan, 1 kali pada trimester pertama, 1 kali pada trimester kedua, dan 2 kali pada trimester ketiga. ${ }^{4}$ Ibu hamil sebaiknya dianjurkan kontak dengan bidan atau dokter sedini mungkin semenjak dirinya hamil untuk mendapatkan pelayanan/asuhan antenatal. Pelayanan antenatal adalah pelayanan kesehatan oleh tenaga kesehatan profesional (dokter spesialis kandungan dan kebidanan, dokter umum, bidan, dan perawat) kepada ibu hamil selama masa kehamilan yang mengikuti pedoman pelayanan antenatal yang ada dengan titik berat pada kegiatan promotif dan preventif. Jadi asuhan antenatal adalah metode pendeteksian yang melibatkan pemeriksaan rutin sejak masa kehamilan dini, sehingga jika ada kemungkinan ketidaknormalan pada janin petugas kesehatan yang menangani dapat segera mengambil tindakan. ${ }^{4}$

Salah satu tanggung jawab sektor kesehatan adalah menjamin tersedianya pelayanan kesehatan yang bermutu, merata dan terjangkau untuk masyarakat. Penyelenggara pelayanan kesehatan tidak semata-mata berada di tangan pemerintah, melainkan mengikut sertakan sebesarbesarnya peran serta aktif segenap anggota masyarakat dan berbagai potensi swasta di bidang kesehatan. Salah satu penyedia fasilitas pelayanan kesehatan yang memiliki peran yang sangat penting berupa kontribusi dalam penyelenggaraan dalam upaya mempercepat peningkatan derajat kesehatan masyarakat Indonesia adalah puskesmas. $^{5}$

Ukuran pelayanan kesehatan yang bermutu yaitu yang mencakup penilaian kepuasan pasien mengenai kinerja pelayanan rumah sakit. Secara umum disebutkan bahwa semakin efektif pelayan yang diberikan maka makin tinggi pula mutu pelayanan tersebut. Selanjutnya dimensi atau indikator untuk mengukur kualitas jasa / pelayanan difokuskan menjadi 5 dimensi : 6

1) Tangible (berwujud); meliputi penampilan fisik dari fasilitas, peralatan, karyawan dan alat-alat komunikasi.

2) Realibility (keandalan); yakni kemampuan untuk melaksanakan 
jasa yang telah dijanjikan secara konsisten dan dapat diandalkan (akurat).

3) Responsiveness (cepat tanggap); yaitu kemauan untuk membantu pelanggan (konsumen) dan menyediakan jasa/ pelayanan yang cepat dan tepat.

4) Assurance (kepastian); mencakup pengetahuan dan keramah-tamahan para karyawan dan kemampuan mereka untuk menimbulkan kepercayaan dan keyakinan, kesopanan dan sifat dapat dipercaya yang dimiliki para staf, bebas dari bahaya, risiko atau keragu-raguan.

5) Empaty (empati); meliputi pemahaman pemberian perhatian secara individual kepada pelanggan, kemudahan dalam melakukan komunikasi yang baik, dan memahami kebutuhan pelanggan.

\section{METODE PENELITIAN}

Jenis penelitian yang digunakan adalah survey analisis deskriptif. Rancangan penelitiaan ini merupakan rancangan penelitiaan sederhana atau sampling survey yang dilakukan dengan tujuan untuk mengetahui kepuasaan pasien ANC terhadap mutu pelayanan kesehatan melalui 5 dimensi mutu oleh Parasuraman.
Pengambilan data primer dilakukan dengan menggunakan kuesioner. Sampel dalam penelitian ini adalah semua populasi yang memenuhi kriteria akan dijadikan sampel. Pengambilan sampel dilakukan dengan menggunakan teknik simple random sampling pada pasien antenatalcare yang terdapat pada puskesmas di wilayah kerja Kecamatan Sombaopu Kabupaten Gowa. Perhitungan jumlah sampel diperoleh dengan menggunakan Rumus Slovin $(\mathrm{N}=111$ dan $\alpha=5 \%)$.

Data yang telah dikumpulkan kemudian diolah secara manual dan dengan menggunakan program Microsoft Excel dan SPSS 16.0. Pengujian hipotesis menggunakan uji Korelasi Spearmen Rho, di mana hubungan dianggap bermakna jika $\mathrm{R}$ hitung $>\mathrm{R}$ tabel, atau $\mathrm{P}$ value $<0,01$. Nilai R tabel diperoleh dari tabel $\mathrm{R}$ product moment, dengan $\mathrm{P}=0,01$ dan $\mathrm{df}=82-2=80$.

\section{HASIL DAN PEMBAHASAN}

Pengukuran tingkat kepuasan pasien dilakukan dalam upaya peningkatan mutu pelayanan kesehatan. Melalui pengukuran tingkat kepuasan tersebut, maka dapat diketahui sejauh mana dimensidimensi mutu pelayanan kesehatan yang telah diselenggarakan oleh puskesmas dapat memenuhi harapan pasien. Pengguna jasa pelayanan kesehatan di Puskesmas menuntut pelayanan yang berkualitas tidak 
hanya menyangkut kesembuhan dari penyakit secara fisik akan tetapi juga menyangkut kepuasan terhadap sikap, pengetahuan dan keterampilan petugas dalam memberikan pelayanan serta tersedianya sarana dan prasarana yang memadai dan dapat memberikan kenyamanan. Dengan semakain meningkatnya kualitas pelayanan maka fungsi pelayanan di puskesmas perlu di tingkatkan agar menjadi lebih efektif dan efisien serta memberikan kepuasan terhadap pasien dan masyarakat. Fungsi Puskesmas yang sangat berat dalam memberikan pelayanan kepada masyarakat dihadapkan pada beberapa tantangan dalam hal sumberdaya manusia dan peralatan kesehatan yang semakin canggih, namun harus tetap memberikan pelayanan yang terbaik. $^{7}$

Hasil penelitian menunjukkan bahwa pada umumnya presentase responden terbesar adalah kelompok umur 26-30 tahun yaitu sebanyak 37,8 \% atau berjumlah 31 responden dan terendah adalah 7,3 \% yaitu 6 responden dari kelompok umur 36-40 tahun (Tabel 1.). Secara keseluruhan distribusi pekerjaan terbanyak adalah lain-lain atau Ibu Rumah Tangga yaitu $87,8 \%$ atau sebanyak 72 responden (Tabel 2.)

Untuk dimensi kepuasan tangibles atau penampilan fisik responden terbanyak menyatakan biasa-biasa saja 75,6\% (Tabel
3.), pada dimensi reliability atau kehandalan responden menyatakan setuju sebesar $72 \%$ (Tabel 4.), pada dimensi emphaty responden terbanyak menyatakan biasa-biasa sebesar 74,4\% (Tabel 5.), pada dimensi responsiveness atau daya tanggap responden terbanyak menyatakan setuju sebesar 82,9\% (Tabel 6.), sedangkan untuk dimensi kepuasan assurance jaminan responden terbanyak menyatakan setuju sebesar 82,9\% (Tabel 7.).

Namun jika dilihat secara keseluruhan tingkat kepuasan pasien sudah baik ditunjukkan dengan $52.4 \%$ pasien yang merasa puas (Tabel 8.). Hasil ini sesuai dengan penelitian sebelumnya dari Aditya (2011) yang mempunyai hasil yaitu kepuasan sedang terhadap mutu pelayanan di puskesmas Nglipar II. $^{8}$ Hal ini menunjukkan bahwa pasien memberikan kepercayaan kepada pihak puskesmas untuk merawat dirinya dan menggambarkan bahwa pihak puskesmas telah menerapkan konsep dimensi mutu layanan kesehatan. Peneliti lain (Wiwik, 2009) juga menemukan hal serupa yaitu mayoritas responden berada pada tindakan cukup puas. ${ }^{9}$ Hal ini sesuai dari pernyataan Lupiyoadi (2009) yang menyatakan bahwa salah satu faktor yang menentukan tingkat keberhasilan dan kualitas perusahaan dalam hal ini adalah fasilitas dan pelayanan kesehatan. Keberhasilan perusahaan dalam memberikan layanan yang bermutu kepada 
para pelanggannya akan berakibat pada pencapaian pangsa pasar yang tinggi, serta meningkatkan profit perusahaan tersebut. Konsekuensi atas pendekatan kualitas pelayanan suatu produk jasa memiliki esensi penting bagi strategi perusahaan untuk mempertahankan diri dan mencapai kesuksesan dalam menghadapi persaingan. ${ }^{10}$

Sedangkan hubungan tingkat kepuasan dan dimensi pelayanan dinilai melalui uji korelasi antara keduanya menggunakan Spearman Rho yang menunjukkan adanya hubungan yang bermakna $(\mathrm{P}<0,01)$ antara tingkat kepuasan terhadap seluruh dimensi pelayanan, yaitu Tangibles, Reliability, Emphaty, Responsiveness dan Assurance (Tabel 9.). Pelayanan merupakan alat utama bagi perusahaan guna memenangkan persaingan dengan perusahaan jasa lain, dengan semakin baik pelayanan maka konsumen atau pelanggan pasti berusaha untuk menggunakan jasa dari perusahaan. Namun ada pula penelitian sebelumnya yang bertentangan dengan hasil penelitian ini yaitu penelitian yang dilakukan oleh (Setyaningsih, et al., 2009) yang menyatakan bahwa tidak ada hubungan antara mutu pelayanan dengan kepuasan pasien terhadap pelayanan petugas. ${ }^{9} \mathrm{Hal}$ ini bertentangan karena pada penelitian ini terdapat hubungan yang bermakna terhadap dimensi-dimensi mutu pelayanan dengan tingkat kepuasan pasien antenatal care. Selain itu, penelitian Setyaningsih et al. tersebut tidak mengkaji dimensi-dimensi mutu pelayanan secara keseluruhan.

\section{KESIMPULAN}

Berdasarkan hasil penelitian ini ditemukan bahwa tingkat kepuasan pasien antenatal care di wilayah kerja Kecamatan Sombaopu Kabupaten Gowa Sulawesi Selatan tahun 2016 sudah baik. Selain itu, terdapat pula hubungan yang bermakna antara dimensi-dimensi mutu pelayanan terhadap tingkat kepuasan pasien antenatalcare (ANC) pada wilayah kerja tersebut.

Peneliti berharap mutu pelayanan kesehatan khususnya pelayanan antenatalcare (ANC) pada puskesmaspuskesmas di wilayah kerja Kecamatan Sombaopu Kabupaten Gowa terus dipertahankan agar kepuasan pasien dapat terus meningkat, namun ada beberapa dimensi kepuasan yaitu tangibles (penampilan fisik) dan emphaty (empati) yang harus ditingkatkan. Selain itu penelitian tingkat kepuasan pasien seperti ini sebaiknya dilakukan secara berkala dan berkesinambunganm sebagai bahan evaluasi kinerja pelayanan kesehatan dan mutu pelayanan. 


\section{DAFTAR PUSTAKA}

1. Hardi, Jon. 2010. Analisis tingkat kepuasan pasien umum dan pasien jamkesmas terhadap mutu pelayanan rawat inap di RSUD Pasaman Barat.

2. Badan Perencanaan Pembangunan Nasional, 2014. Laporan pencapaian Tujuan Pembangunan Millenium Indonesia. Bappenas.

3. Kementerian Kesehatan Republik Indonesia, 2014. Profil Kesehatan Indonesia Tahun 2013, s.1.: Kementerian Kesehatan Republik Indonesia.

4. Badan Penelitian dan Pengembangan Kesehatan Kementerian Kesehatan RI, 2013. Riset Kesehatan Dasar 2013. [Online] Available at: http://www.depkes.go.id/resources/do wnload/general/Hasil\%20Riskesdas\% 202013.pdf [Accessed 28 Sept 2016].

5. Sabarguna, Boy S. Buku Pegangan Mahasiswa Manajemen Rumah Sakit. edisi pertama Jakarta: Sagung Seto, 2011.
6. Parasuraman, A, VA Zeithami, and LL Berry. "Servqual : A Multiple -item scale for measuring consumer perception." Journal of Retaling, 1988: 12.

7. Rustam Efendi, Alwy Arifin,Darmawansyah. Hubungan Mutu Pelayanan Kesehatan Dengan Kepuasan Pasien Rawat Jalan Di Puskesmas Aeng Towa Kabupaten Takalar. 2013

8. Khusnul, Aditya Ariawan \& Ery. Analisis kepuasan pasien terhadap mutu pelayanan pada puskesmas Nglipar Gunungkidul. 2011

9. Setyaningsih, Wiwik, Rita Benya Adriani, and E Prihatin. Mutu Pelayanan dan Tingkat Kepuasan pasien di Klinik Terpadu politeknik Kesehatan Surakarta. 2009.

10. Lupiyoadi, $\mathrm{R}$ dan Hamdani, A. Manajemen Pemasaran Jasa, Jakarta ; Salemba Empat, 2009. 


\section{DAFTAR TABEL}

Tabel 1. Karakteristik usia responden di wilayah kerja kecamatan Somba Opu kabupaten Gowa Tahun 2016.

\begin{tabular}{lcc}
\hline Variabel & $\mathbf{n}$ & $\mathbf{\%}$ \\
\hline \hline Usia & 10 & \\
$15-20$ tahun & 22 & 12,2 \\
$21-25$ tahun & 31 & 26,8 \\
$26-30$ tahun & 14 & 15,8 \\
$31-35$ tahun & 6 & 7,3 \\
$36-40$ tahun &
\end{tabular}

Sumber : Data primer, 2016

Tabel 2. Karakteristik pekerjaan responden di wilayah kerja kecamatan Somba Opu kabupaten Gowa Tahun 2016

\begin{tabular}{lcc}
\hline \hline \multicolumn{1}{c}{ Variabel } & n & \% \\
\hline \hline Pekerjaan & 1 & 1,2 \\
Pegawai Negeri & 5 & 6,1 \\
Pegawai Swasta & 3 & 3,7 \\
Wirawasta & 1 & 1,2 \\
Mahasiswa/Pelajar & 72 & 87,8 \\
Lain-lain & & \\
\hline \hline
\end{tabular}

Sumber : Data primer, 2016

Tabel 3. Analisis deskriptif pada dimensi tangibles (penampilan fisik)

\begin{tabular}{lcc}
\hline \hline \multicolumn{1}{c}{ Variabel } & n & \% \\
\hline \hline Tangibles & & \\
Sangat Tidak Setuju & 3 & 3,7 \\
Tidak Setuju & 8 & 11,0 \\
Biasa-biasa & 62 & 75,6 \\
Setuju & 9 & 9,8 \\
Sangat Setuju & 0 & 0,0 \\
\hline \hline
\end{tabular}

Sumber : Data primer, 2016 
Tabel 4. Analisis deskriptif pada dimensi reliability (kehandalan)

\begin{tabular}{lcc}
\hline \hline \multicolumn{1}{c}{ Variabel } & n & \% \\
\hline \hline Reliability & & \\
Sangat Tidak Setuju & 0 & 0,0 \\
Tidak Setuju & 2 & 2,4 \\
Biasa-biasa & 11 & 13,4 \\
Setuju & 59 & 72,0 \\
Sangat Setuju & 10 & 12,2 \\
\hline \hline
\end{tabular}

Sumber : Data primer, 2016

Tabel 5. Analisis deskriptif pada dimensi Emphaty (empati)

\begin{tabular}{lcc}
\hline \hline \multicolumn{1}{c}{ Variabel } & n & \% \\
\hline \hline Emphaty & & \\
Sangat Tidak Setuju & 0 & 0,0 \\
Tidak Setuju & 9 & 11,0 \\
Biasa-biasa & 61 & 74,4 \\
Setuju & 12 & 14,6 \\
Sangat Setuju & 0 & 0,0 \\
\hline \hline
\end{tabular}

Sumber : Data primer, 2016

Tabel 6. Analisis deskriptif pada dimensi responsiveness (daya tanggap)

\begin{tabular}{lcc}
\hline \hline \multicolumn{1}{c}{ Variabel } & n & \% \\
\hline \hline Responsiveness & & \\
Sangat Tidak Setuju & 0 & 0,0 \\
Tidak Setuju & 2 & 2,4 \\
Biasa-biasa & 5 & 6,1 \\
Setuju & 68 & 82,9 \\
Sangat Setuju & 7 & 8,5 \\
\hline \hline
\end{tabular}

Sumber : Data primer, 2016

Tabel 7. Analisis deskriptif pada dimensi assurance (jaminan)

\begin{tabular}{lcc}
\hline \multicolumn{1}{c}{ Variabel } & n & \% \\
\hline \hline Assurance & & \\
Sangat Tidak Setuju & 0 & 0,0 \\
Tidak Setuju & 2 & 2,4 \\
Biasa-biasa & 5 & 6,1 \\
Setuju & 68 & 82,9 \\
Sangat Setuju & 7 & 8,5 \\
\hline \hline
\end{tabular}

Sumber : Data primer, 2016 
Tabel 8. Tingkat kepuasan pasien di wilayah kerja kecamatan Somba Opu kabupaten Gowa Tahun 2016

\begin{tabular}{lcc}
\hline \hline \multicolumn{1}{c}{ Variabel } & n & \% \\
\hline \hline Tingkat Kepuasan & & \\
Sangat Tidak Setuju & 1 & 1,2 \\
Tidak Setuju & 10 & 12,2 \\
Biasa-biasa & 24 & 29,3 \\
Setuju & 43 & 52,4 \\
Sangat Setuju & 4 & 4,9 \\
\hline \hline
\end{tabular}

Sumber : Data primer, 2016

Tabel 9. Analisis Hubungan Tingkat Kepuasan dan Dimensi Mutu Pelayanan di wilayah kerja kecamatan Somba Opu kabupaten Gowa Tahun 2016

\begin{tabular}{ccccc}
\hline \hline & \multicolumn{3}{c}{ Tingkat Kepuasan } & \multirow{2}{*}{ Kesimpulan } \\
\cline { 2 - 4 } Variabel & R hitung & R tabel & \multirow{2}{*}{ * } & \\
Dimensi Pelayanan & & & \\
Tangibles & 0,450 & 0,283 & 0,000 & Bermakna \\
Reliability & 0,524 & 0,283 & 0,000 & Bermakna \\
Emphaty & 0,615 & 0,283 & 0,000 & Bermakna \\
Responsiveness & 0,453 & 0,283 & 0,000 & Bermakna \\
Assurance & 0,551 & 0,283 & 0,000 & Bermakna \\
\hline \hline
\end{tabular}

*Uji Korelasi Spearman-Rho, $p<0,01$ dinyatakan bermakna.

$(\mathrm{r}=$ nilai korelasi, $\mathrm{P}=$ nilai signifikansi) 